\title{
Potentiometric titration data on the enhancement of sorption capacity of surface-modified biosorbents: functional groups scanning method
}

\author{
Sok $\mathrm{Kim}^{1} \cdot$ Chul Woong $\mathrm{Cho}^{2} \cdot$ Myung-Hee Song ${ }^{2} \cdot$ John Kwame Bediako $^{2} \cdot$ Yeoung-Sang Yun $^{2} \cdot$ Yoon-E Choi $^{1}$
}

Received: 30 December 2017 / Accepted: 10 May 2018 / Published online: 24 May 2018

(c) The Author(s) 2018

\begin{abstract}
In the present study, the relationship between the amount of anionic or cationic binding sites and adsorption capacities of biosorbents is discussed through potentiometric titration and mathematical model equations (proton-binding models). The poly(acrylic) acid-modified biomass (PAAB) and polyethylenimine-modified biomass (PEIB) derived from raw biomass (RB) Corynebacterium glutamicum (C. glutamicum) were used as cationic and anionic binding site-enhanced biosorbents, respectively. To obtain the sorption capacities of biomasses for anionic and cationic pollutants, isotherm tests were carried out using Basic Blue 3 (BB3, at pH 9) and Reactive Red 4 (RR4, at pH 2) as model anionic and cationic pollutants, respectively. The maximum sorption capacity $\left(q_{\mathrm{m}}\right)$ of PAAB was 1.28 times higher than RB for BB3. In the case of PEIB, the sorption capacity was found to be 3.27 times higher than RB for RR4. A quantitative information of functional groups could be estimated by the application of proton-binding models to potentiometric titration results. In addition, the buffering capacities of functional groups were obtained from the parameters of $\mathrm{pK}$ models. An increasing ratio of sorption capacities was similar to that of the buffering capacities of modified biosorbents obtained from all conditions of pK models. Therefore, the fact that the sorption capacity of modified biomass can be predicted by comparing it with the buffering capacity of biosorbents was confirmed.
\end{abstract}

Keywords Biosorption · Potentiometric titration · Biomass $\cdot$ Surface modification · Biosorbent $\cdot$ Buffering capacity

\section{Introduction}

Biosorption has been introduced as an environmental-friendly and cost-effective method. It can replace conventional methods such as precipitation, membrane filtration, ion exchange, solvent extraction, oxidation, and coagulation for treatment of pollutants in the aqueous effluents (Wei et al. 2015). In the

Electronic supplementary material The online version of this article (https://doi.org/10.1007/s10098-018-1542-2) contains supplementary material, which is available to authorized users.

Yeoung-Sang Yun ysyun@jbnu.ac.kr

$\triangle$ Yoon-E Choi yechoi@korea.ac.kr

1 Division of Environmental Science and Ecological Engineering, College of Life Sciences and Biotechnology, Korea University, Seoul 02841, Republic of Korea

2 Division of Semiconductor and Chemical Engineering, Chonbuk National University, Jeonju 54896, Republic of Korea biosorption process for the removal of ionic pollutants, various biotic materials such as bacteria, fungi, algae, agricultural, and industrial byproducts, and other biomaterials can be applied as biosorbents (Won et al. 2014). According to Volesky (2007), these biomasses possess various functional groups (e.g., carboxyl, amine, hydroxyl, and sulfonate) on their surface. These binding sites can bind ionic materials like metals and dyes by complex physicochemical mechanisms including ion exchange, complexation/coordination, surface precipitation, adsorption, electrostatic interaction, and chelation (Vijayaraghavan and Yun 2008). Recently, as per the acquired knowledge on biosorption mechanisms, various methods of functional group modification such as addition of binding sites, removal of interfering sites, and coating/composite with ionic polymers have been applied to improve the sorption capacity (Kim et al. 2016a). Among these modification methods, cases of the sorbents-applied ionic polymers such as polyethylenimine (PEI) (Cho et al. 2016), poly(allylamine hydrochloride) (PAA HCl) (Mao et al. 2010), and poly(methacrylic acid) (PMA) (Yu et al. 2009) showed a drastic enhancement in the sorption capacity because ionic polymers possess a large 
number of binding sites in their chemical structures for target pollutants.

Since amounts and kinds of binding sites in biosorbents are important factors for determining the sorption capacity of biosorbents, quantitative and qualitative characteristics evaluation of functional groups on the biosorbents should be essential in biosorption research area. To determine the characteristics of functional groups on the biosorbents, various surface analyses including Fourier-transform infrared spectroscopy (FT-IR) (Ramrakhiani et al. 2011), X-ray photoelectron spectroscopy (XPS) (Kim et al. 2018), and potentiometric titration methods (Bhatnagar et al. 2012) have been applied. Of these analytical methods, potentiometric titration method can be available for the simultaneous qualitative and quantitative analyses of functional groups in the biosorbents. The potentiometric titration curves of biosorbents present the surface characteristics ( $\mathrm{pK}_{\mathrm{a}}$ positions) depending on the possessed functional groups in the biosorbents (biomasses). In addition, the amounts of functional groups in the biomasses have been estimated by applying the mathematical model equation (i.e., proton-binding model) to the experimental potentiometric titration data (Kim et al. 2016a). According to the published report on Microcystis aeruginosa and Chlorella vulgaris by Hadjoudja et al. (2010), information on quantitative functional groups was estimated through potentiometric titration. In addition, by the potentiometric titration and proton-binding model, Won et al. (2013) calculated the quantitative profile of activated binding sites in the sewage sludge biomass depending on the solution $\mathrm{pH}$ and discussed the $\mathrm{pH}$ influence in $\mathrm{Cd}(\mathrm{II})$ adsorption capacity. Although the potentiometric titration is a useful methodology for analysis of functional group characteristics in the biosorbents, it has been accessorily applied for just surface characterization of the biosorbents in almost biosorption studies. As we described above, it is expected that the enhanced amount of functional groups on the surface-modified biosorbents can be derived from the potentiometric titration curves and proton-binding model. Also, by comparing with quantitative information of binding sites and sorption capacity of modified and raw biosorbents, the relationship between enhanced sorption capacity and binding site amount can be discussed. However, detailed discussions about this possibility were not yet reported. Therefore, in the present study, we investigated the relationship between the enhanced number of binding sites and enhanced sorption capacities of biosorbents.

\section{Materials and methods}

\section{Materials}

The dyes, BB3 and RR4, used as model ionic pollutants for adsorption experiments were purchased from Sigma-Aldrich
Korea Ltd. (Yongin, Korea). The ionic polymers, PEI (M.W. $70,000)$ and PAA ( M.W. 4,000,000) were purchased from Hap-Jung Co. (Seoul, Korea) and Polysciences, Inc. (USA), respectively. $25 \mathrm{wt} \%$ glutaraldehyde (GA) and epichlorohydrin $(\mathrm{ECH},>99 \%)$ were supplied by Junsei Chemical Co. Ltd. and Sigma-Aldrich Ltd., respectively. Other chemicals used in this study were of analytical grade. As RB, C. glutamicum was obtained in a dried powder form from amino acid fermentation industry (Daesang, Kunsan, Korea). For potentiometric titration and isotherm experiments, the RB was washed one time using distilled water at low $\mathrm{pH}(\mathrm{pH}$ $1.8-\mathrm{pH} 2.2$ ) to remove any media present on the RB surface.

\section{Preparation of surface-modified biosorbents}

For fabricating the PEI-modified biomass (PEIB), $50 \mathrm{~g}$ of $\mathrm{RB}$ was mixed with $1 \mathrm{~L}$ of PEI solution $(10 \mathrm{~g} / \mathrm{L})$ for $2 \mathrm{~h}$. Thereafter, $6 \mathrm{~mL}$ of $25 \%$ GA was added in the biomass/PEI mixture for cross-linking for $3 \mathrm{~h}$ at room temperature. After cross-linking, PEIB was separated by centrifugation and washed three times using distilled water and freeze-dried for $24 \mathrm{~h}$. In the case of PAA-modified biomass (PAAB), $50 \mathrm{~g}$ of dried RB was agitated with $1 \mathrm{~L}$ of $5 \% \mathrm{w} / \mathrm{v}$ PAA solution. That mixture was mixed for $10 \mathrm{~h}$ at room temperature. Simultaneously, $8 \mathrm{~mL}$ of concentrated $\mathrm{HCl}$ was added as a catalyst for PAA modification on the biomass. After PAA modification, the mixture was centrifuged for PAA-coated biomass separation and washed two times using distilled water for removing any residual $\mathrm{HCl}$ and PAA from the solution. Thereafter, the prepared PAAB was cross-linked in the $1 \mathrm{~L}$ of ECH solution $(2 \mathrm{~mL} / \mathrm{L})$ for $2 \mathrm{~h}$ at room temperature. After cross-linking, the cross-linked PAAB was separated by centrifugation. The obtained PAAB was washed three times with distilled water and freeze-dried.

\section{FT-IR analysis}

To determine the characteristics of functional groups for $\mathrm{RB}, \mathrm{PEIB}$, and PAAB, Fourier-transform infrared spectrometer (FT-IR, JASCO, Japan) analyses were carried out. The spectrums of biomasses were recorded in the FT-IR within the range of $4000-400 \mathrm{~cm}^{-1}$ with samples prepared as $\mathrm{KBr}$ disks.

\section{Zeta potential measurements}

To prepare samples for zeta potential measurement of biomasses, biomasses were prepared as fine particles (below $65 \mu \mathrm{m}$ ) by sieve. $0.1 \mathrm{~g}$ of each prepared biomass was suspended in $200 \mathrm{~mL}$ of distilled water. The suspensions were divided as $20 \mathrm{~mL}$ in $50 \mathrm{~mL}$ polypropylene tubes. Then $\mathrm{pH}$ of each sample was adjusted in the $\mathrm{pH}$ range $2-10$ by using $0.1 \mathrm{M} \mathrm{NaOH}$ and $0.1 \mathrm{M} \mathrm{HCl}$ solution. Zeta potential of 
biomasses were measured using a zeta potential and particle size analyzer (ELS-6000, Otasuka Electronic Co.).

\section{Isotherm experiment}

To evaluate the maximum sorption capacities of the RB, PEIB, and PAA, isotherm experiments were carried out using BB3 and RR4 as positively and negatively charged sorbates for biomasses (BB3: RB and PAAB, RR4: RB and PEIB), respectively. RR4 and BB3 solutions were prepared by diluting stock dye solutions with distilled water to desired concentrations $(100-3000 \mathrm{mg} / \mathrm{L})$. Then, $0.15 \mathrm{~g}$ of biomasses and $30 \mathrm{~mL}$ of dye solutions were agitated for $24 \mathrm{~h}$ at $25^{\circ} \mathrm{C}, 160 \mathrm{rpm}$. During the sorption process, the $\mathrm{pH}$ of samples was maintained using $1 \mathrm{M} \mathrm{NaOH}$ and $1 \mathrm{M} \mathrm{HCl}$ solution (RR4: $\mathrm{pH}$ 2, BB3: $\mathrm{pH}$ 9). After the equilibrium state was reached, the final $\mathrm{pH}$ was checked, and the samples were taken and centrifuged for liquid-solid separation. The supernatant portion was used to analyze the concentration of residual dye after proper dilution. The dye concentration of RR4 and BB3 in the diluted samples was determined using a spectrophotometer (UV-2550, Shimadzu, Kyoto, Japan) at 517 and $654 \mathrm{~nm}$, respectively. The uptake of cation and anion dyes was calculated by the following equation:

$q=\frac{\left(C_{0} V_{0}-C_{\mathrm{f}} V_{\mathrm{f}}\right)}{X}$,

where $q(\mathrm{mg} / \mathrm{g})$ is the amount of dye adsorbed per gram of biomass; $C_{0}$ and $C_{\mathrm{f}}$ are the initial and final concentration $(\mathrm{mg} / \mathrm{L})$ of dyes, respectively; $V_{0}$ and $V_{\mathrm{f}}$ are the initial and final (initial plus added titrant solutions) volumes (L), respectively; and $X(\mathrm{~g})$ indicates the weight of the biomass.

\section{Potentiometric titration experiments}

To estimate the quantitative information of functional groups of biomasses, the potentiometric titration experiments were performed. For these experiments, $4 \mathrm{~g}$ of each biomass (RB, PEIB, and PAAB) was suspended in $800 \mathrm{~mL}$ of $0.1 \mathrm{M} \mathrm{NaCl}$ solution $\left(\mathrm{CO}_{2}\right.$ free $)$ and initial $\mathrm{pH}$ of suspensions was controlled to $\mathrm{pH} 2$ or 11 using $1 \mathrm{M} \mathrm{HCl}$ and $1 \mathrm{M} \mathrm{NaOH}$ solution (0.1 M NaCl solution based). By dispensing $20 \mathrm{~mL}$ of suspensions in $50 \mathrm{~mL}$ of polyethylene tubes, the total thirty-five samples were prepared for titraion experiments. Then, different volumes of $0.5 \mathrm{M} \mathrm{HCl}$ and $0.5 \mathrm{M} \mathrm{NaOH}$ solution $(0.1 \mathrm{M}$ $\mathrm{NaCl}$ solution based) were added to the biomass suspended samples. The samples were agitated in a shaker at $160 \mathrm{rpm}$ and room temperature $\left(25 \pm 0.2^{\circ} \mathrm{C}\right)$ for over $12 \mathrm{~h}$ to achieve proton sorption equilibrium. Finally, the equilibrium $\mathrm{pH}$ of each sample was measured using an electrode (Ingold). During the potentiometric titration experiments, $\mathrm{CO}_{2}$-free condition was maintained through $\mathrm{N}_{2}$ gas purging to avoid the influence of inorganic carbon on the $\mathrm{pH}$ of solutions. The potentiometric titration experiments were single-tried.

\section{Results and discussion}

\section{Surface characteristics of biomasses}

To determine the variations in functional groups on the biomasses, FT-IR analyses were carried out. The obtained FT-IR spectrums for RB, PEIB, and PAAB are displayed in Fig. 1. According to the FT-IR results of RB (Fig. 1a), various adsorption peaks were observed at around 3600-3200, $1661,1536,1402,1242,1157$, and $1067 \mathrm{~cm}^{-1}$ owing to multifarious functional groups on the surface of biomass (Yu et al. 2009). The absorption peaks in the range $3200-3600 \mathrm{~cm}^{-1}$ overlapped the IR peaks for $-\mathrm{OH}$ groups and the $-\mathrm{NH}$ asymmetric stretching of amine groups on the biomass (Fang et al. 2009). The peaks at 1242 and $1157 \mathrm{~cm}^{-1}$ represent the $\mathrm{COO}^{-}$groups of carboxylate groups (Naja et al. 2005). The strong peaks at $1661 \mathrm{~cm}^{-1}$ (Singh et al. 2014) and $1536 \mathrm{~cm}^{-1}$ (Kim et al. 2016b) indicate the amide I and II bands and/or $\mathrm{C}=\mathrm{O}$ chelate stretching of carboxyl groups. The peaks at 1536 and $1242 \mathrm{~cm}^{-1}$ are attributed to C-N stretching (Choi and Yun 2006). The peak at $1402 \mathrm{~cm}^{-1}$ can be assigned to $\mathrm{C}=\mathrm{O}$ symmetric stretching in carboxylate ions (Yu et al. 2009). In addition, absorption peaks around $1157 \mathrm{~cm}^{-1}(\mathrm{P}=\mathrm{O}$ stretching $)$ and $1067 \mathrm{~cm}^{-1}(\mathrm{P}-\mathrm{OH}$ stretching) were observed (Kim et al. 2015). After the modification of the biomass, some peaks were changed (Fig. 1b, c). In case of PAAB (Fig. 1b), the FT-IR peaks at 1242, 1157, and $1402 \mathrm{~cm}^{-1}$, which represented carboxyl groups on the biomass surface, increased. A new peak at $1583 \mathrm{~cm}^{-1}$ was observed, which might be assigned to asymmetric stretching

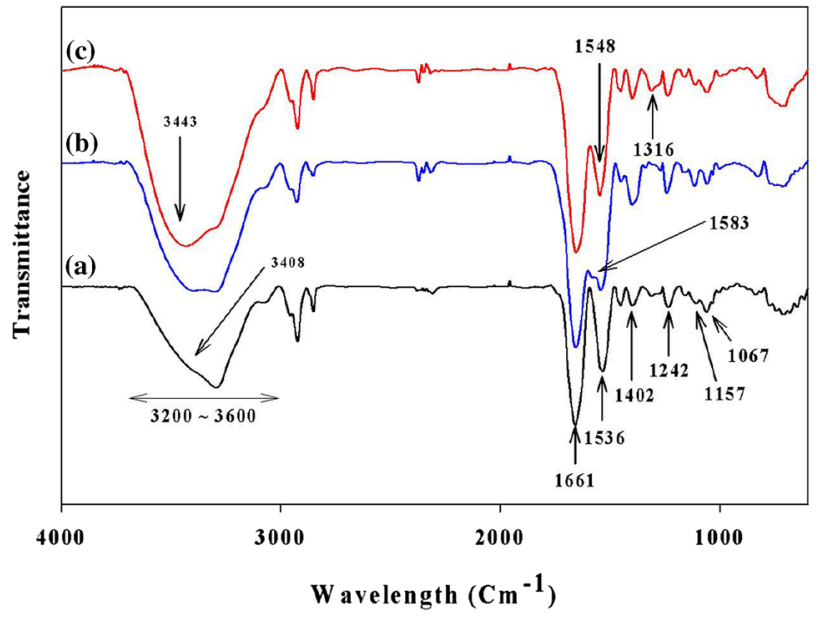

Fig. 1 Results of FT-IR (a: raw C. glutamicum, b: PAAB, and c: PEIB) 
in deprotonated carboxyl groups (Korkmaz et al. 2013). In addition, the peak around $3408 \mathrm{~cm}^{-1}$ broadened. In case of PEIB (Fig. 1c), the broad overlapping peak shifted to $3443 \mathrm{~cm}^{-1}$ and increased owing to the enhancement of amine groups introduced from PEI. The $\mathrm{C}-\mathrm{N}$ stretching peak at $1536 \mathrm{~cm}^{-1}$ shifted to $1548 \mathrm{~cm}^{-1}$. Based on the FT-IR result of $\mathrm{RB}$, the $\mathrm{RB}$ possesses various functional groups on the surface, such as carboxyl, phosphonate, and amine groups. In addition, the FT-IR results showed that PEIB and PAAB were successfully modified by PEI and PAA, respectively. The modified functional groups can be determined as zeta potential results of biomasses (Fig. 2). As seen in Fig. 2, the surface of RB and PAAB was negatively charged in the acidic condition (around $\mathrm{pH} 3$ ). However, the surface charge of PAAB was more negative compared to that of RB above $\mathrm{pH} 4$. The carboxyl groups can be negatively charged above their $\mathrm{pK}_{\mathrm{a}}$ value ( $\left.\mathrm{pH} 3-5\right)$ by the deposition of the proton ion. Therefore, this result indicates that higher amount of carboxyl groups is located on the PAAB. The surface of PEIB was positively charged compared to that of RB in all range of the $\mathrm{pH}$ solution, because large amounts of amine groups, which can be charged positively at $\mathrm{pHs}$ below their $\mathrm{pK}_{\mathrm{a}}$ values ( $\left.\mathrm{pH} 8-11\right)$, are introduced by PEI modification.

Based on these results, it can be expected that the sorption capacities of modified biomasses (PAAB and PEIB) may be higher than that of RB for the ionic pollutants, because binding sites for ionic pollutants increased. Thus, the experimental sorption tests were carried out to estimate the ionic pollutant uptakes of modified biomasses using RR4 and BB3 dyes as negatively and positively charged pollutants, respectively.

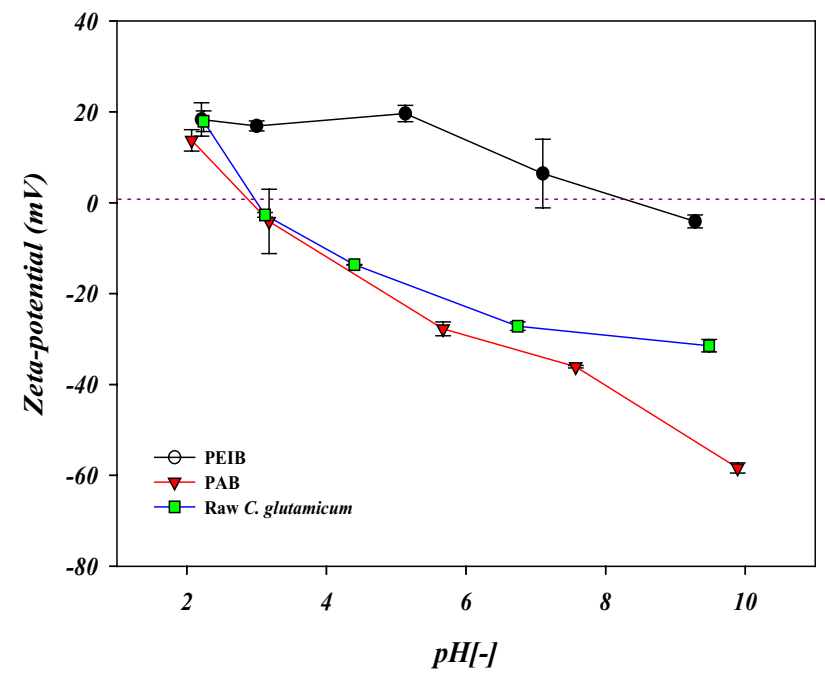

Fig. 2 Zeta potential of biosorbents range of $\mathrm{pH} \sim 2-10$. Zeta potential measurements were triplicated. The error bars indicate the standard deviation

\section{Comparison of sorption performance}

For comparing the maximum sorption capacities $\left(q_{\mathrm{m}}\right)$ of RB and $\mathrm{PAAB}$, isotherm experiments were carried out by using BB3 (positively charged dye) at $\mathrm{pH}$ 9; here, carboxyl groups were fully negatively charged $\left(-\mathrm{COO}^{-}\right)$by deprotonation. Similarly, for comparing the maximum sorption capacities of RB and PEIB, isotherm experiments were carried out by using RR4 (negatively charged dye) at $\mathrm{pH} 2$; here, the amine groups were fully positively charged $\left(-\mathrm{NH}_{3}{ }^{+}\right)$due to protonation of amine groups. The experimental isotherm results of biomasses for RR4 and BB3 are displayed in Fig. 3. As shown in Fig. 3, the sorption uptakes of biomasses increased with increasing concentration of model dyes and reached to the equilibrium states above the specific concentration of dyes. In addition, the sorption capacities of modified biomasses showed higher values than those of RB for RR4 and BB3. To estimate the maximum uptake of biomasses for ionic pollutants, the Langmuir isotherm equation was
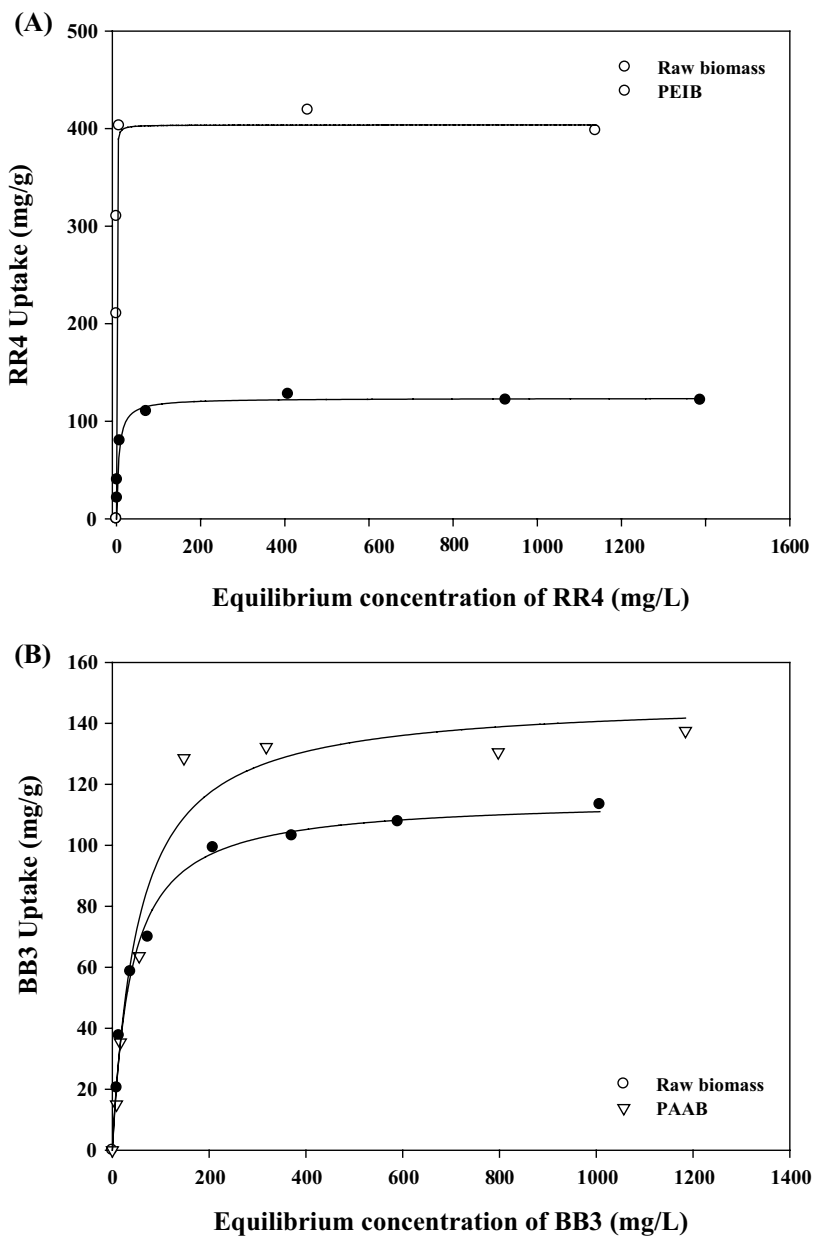

Fig. 3 The isotherm results of $\mathbf{A}$ RB and PEIB for RR4 at pH 2 and $\mathbf{B}$ $\mathrm{RB}$ and $\mathrm{PAAB}$ for $\mathrm{BB} 3$ at $\mathrm{pH} 9$ 
applied to the experimental results. The Langmuir isotherm equation can be written as

$q=\frac{q_{\mathrm{m}} b C_{\mathrm{f}}}{1+b C_{\mathrm{f}}}$,

where $q(\mathrm{mg} / \mathrm{g})$ is the experimentally estimated sorption capacity of biomasses for ionic pollutants. $q_{\mathrm{m}}$ is the maximum sorption capacity $(\mathrm{mg} / \mathrm{g})$ defined by the Langmuir model equation. $C_{\mathrm{f}}$ is the equilibrium concentration of the pollutant in solution $(\mathrm{mg} / \mathrm{L})$, and $b$ is the Langmuir equilibrium constant $(\mathrm{L} / \mathrm{mg})$. The estimated Langmuir parameters $\left(q_{\mathrm{m}}\right.$ and $\left.b\right)$ of RB, PAAB, and PEIB are summarized in Table 1.

As shown in Table 1, the maximum sorption capacity and Langmuir constant of the RB for RR4 were estimated to be $123.57 \pm 3.56 \mathrm{mg} / \mathrm{g}$ and $0.189 \pm 0.03 \mathrm{~L} / \mathrm{mg}$ at $\mathrm{pH} 2$, respectively. After PEI modification, the maximum sorption capacity of PEIB was enhanced 3.27 times $(403.72 \pm 31.81 \mathrm{mg} / \mathrm{g})$ at the same $\mathrm{pH}$. In addition, the Langmuir constant also recorded higher values of $6.09 \pm 2.997 \mathrm{~L} / \mathrm{mg}$. In the case of the BB3 isotherm, the maximum sorption capacities and Langmuir constants of RB were calculated as $115.21 \pm 2.55 \mathrm{mg} / \mathrm{g}$ and $0.026 \pm 0.003 \mathrm{~L} / \mathrm{mg}$ at $\mathrm{pH} 9$, respectively. The maximum sorption capacity of $\mathrm{PAAB}$ for $\mathrm{BB} 3$ at $\mathrm{pH} 9$ was estimated to be $148.04 \pm 8.06 \mathrm{mg} / \mathrm{g}$. It was 1.28 times higher than maximum sorption capacity of RB for BB3. The Langmuir constant of $\mathrm{PAAB}$ was recorded to be $0.019 \pm 0.005 \mathrm{~L} / \mathrm{mg}$. As discussed in the results of zeta potential measurements, the enhancement in the maximum sorption capacities for modified biomasses might be owing to the enhancement in the amount of binding sites (carboxyl groups and amine groups) for ionic pollutants by ionic polymer modification on the biomass. For determining the relation between sorption capacity and amount of binding sites of the sorbents, a quantitative analysis of functional groups in the biomass was carried out using potentiometric titration and mathematical modeling.

\section{Quantitative analysis of functional groups}

The potentiometric titration results of RB, PEIB, and PAAB are displayed in Fig. 4. As shown in Fig. 4, the titration

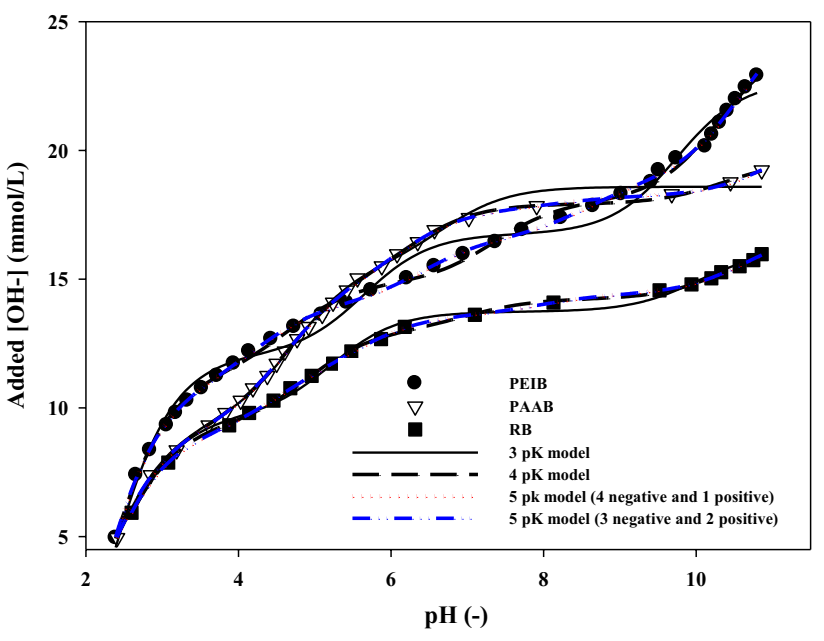

Fig. 4 Results of potentiometric titration for RB, PAAB, and PEIB

curves of biomasses showed the characteristics of functional groups in the biomasses. The modified biomasses required higher amount of $\left[\mathrm{OH}^{-}\right]$ions to reach the same $\mathrm{pH}$ of $\mathrm{RB}$ and enhanced in buffering ranges of the titration curves at specific $\mathrm{pH}$ ranges. The buffering range was reinforced at around $\mathrm{pH} 4$ in the case of $\mathrm{PAAB}$, while the buffering range was reinforced above $\mathrm{pH} 7$ in the case of PEIB, which is higher than that of RB. These results indicated that higher amount of protons could be neutralized with $\left[\mathrm{OH}^{-}\right]$ions released from functional groups of modified biomasses than that of RB. To obtain detailed quantitative information of functional groups, the proton-binding model (Eq. 3) was applied to the 33,25 , and 20 numbers of titration data points for PEIB, PAAB, and RB, respectively, in the range of $\mathrm{pH}$ 2.5-11. The proton-binding model (Eq. 3) considered the reaction with a proton and related equilibrium constant $\left(K_{j}\right)$ of a functional groups $\left(B_{j} H\right)$, and could be driven by considering the mass balance of functional groups and the electroneutrality as follows:

$$
\begin{aligned}
{\left[\mathrm{Na}^{+}\right]_{\mathrm{added}}=} & {\left[\mathrm{OH}^{-}\right]_{\mathrm{added}}=\sum_{i=1}^{M} \frac{b_{i} X}{1+\left[H^{+}\right] / K_{i}} } \\
& -\sum_{j=1}^{N} \frac{\left(1+K_{j}\right) b_{j} X}{\left[H^{+}\right]}+\frac{K_{\mathrm{w}}}{\left[H^{+}\right]}-\left[H^{+}\right],
\end{aligned}
$$

Table 1 Estimated parameters from Langmuir isotherm equation

\begin{tabular}{lllllll}
\hline Dyes & Sorption $\mathrm{pH}$ & Sorbents & Parameters & & $\begin{array}{l}\text { Enhance- } \\
\text { ment } \\
\text { (times) }\end{array}$ \\
\hline RR4 & 2 & & $q_{\mathrm{m}}(\mathrm{mg} / \mathrm{g})$ & $b(\mathrm{~L} / \mathrm{mg})$ & $R^{2}$ & \\
& & RB & $123.57 \pm 3.56$ & $0.189 \pm 0.030$ & 0.985 & 1 \\
BB3 & 9 & PEIB & $403.72 \pm 31.81$ & $6.090 \pm 2.997$ & 0.913 & 3.27 \\
& & RB & $115.21 \pm 2.55$ & $0.026 \pm 0.003$ & 0.993 & 1 \\
& & PAAB & $148.04 \pm 8.06$ & $0.019 \pm 0.005$ & 0.972 & 1.28 \\
\hline
\end{tabular}

The error values of each parameter indicate the standard error calculated from Langmuir isotherm equation 
where $\left[\mathrm{OH}^{-}\right]_{\text {added }}$ is the concentration of added hydroxide ions ( $\mathrm{mmol} / \mathrm{L}), K$ is the proton dissociation constant, and $b$ and $X$ represent the molar quantities of the functional groups on the biomass surface ( $\mathrm{mmol} / \mathrm{g}$ ) and the biomass concentration $(\mathrm{g} / \mathrm{L})$, respectively. Subscripts $i$ and $j$ indicate negatively and positively charged groups, respectively. $M$ and $N$ denote the type of charged functional groups. Detailed procedure for derivation of Eq. 3 was presented in the supplementary information.

According to the FT-IR results of biomasses, at least three types of functional groups, such as carboxyl, phosphonate, and amine groups, are located on the biomasses. Therefore, various proton-binding models, regarding 3-5 types of functional groups on the biomasses (3-pK, 4-pK, and 5-pK models), were designed and applied to potentiometric titration results. The obtained parameters from proton-binding models are summarized in Table 2. As shown in Fig. 4 and Table 2, the 3-pK model was initially applied. Although the coefficients of determination $\left(R^{2}\right)$ for the 3-pK model were higher than $0.99\left(R_{3, \mathrm{RB}}^{2}=0.9962\right.$, $R_{3, \text { PEIB }}^{2}=0.9913$, and $\left.R_{3, \mathrm{PAAB}}^{2}=0.9970\right)$, it was not sufficient to represent the titration results. Therefore, $4-\mathrm{pK}$ and 5-pK models were used to fit the titration results of biomasses. The $R^{2}$ of 4-pK and 5-pK models was estimated above 0.998 for RB, PEIB, and PAAB. In all pK models, the first groups of $\mathrm{pK}_{\mathrm{a}}$ values of $\mathrm{RB}, \mathrm{PEIB}$, and PAAB were recorded at around $2(4-\mathrm{pK}, 2.20 \pm 0.03,2.14 \pm 0.04$, and $2.16 \pm 0.04$; 5 -pK-a, $2.17 \pm 0.02,2.09 \pm 0.03$, and $2.15 \pm 0.09$; 5-pK-b, $2.13 \pm 0.02,2.02 \pm 0.03$, and $2.14 \pm 0.07$, respectively). However, these first $\mathrm{pK}_{\mathrm{a}}$ values of biomasses were not present in the studied $\mathrm{pH}$ range of the titration results. Hence, these functional groups corresponding to the observed $\mathrm{pK}_{\mathrm{a}}$ values are ignored in further discussions. According to results from the 4-pK model, the second, third and fourth $\mathrm{pK}_{\mathrm{a}}$ values for $\mathrm{RB}$ were calculated as $4.93 \pm 0.06,7.21 \pm 0.21$, and $10.72 \pm 0.13$, respectively. The amounts of functional groups were estimated to be $0.74 \pm 0.03,0.26 \pm 0.03$, and $0.58 \pm 0.06 \mathrm{mmol} / \mathrm{g}$, respectively. Meanwhile, the $\mathrm{pK}_{\mathrm{a}}$ values of PEIB $(4.70 \pm 0.11,7.39 \pm 0.12$, and $10.37 \pm 0.07)$ and PAAB $(4.62 \pm 0.04,6.31 \pm 0.07$, and $10.71 \pm 0.14)$ were estimated to be similar to the values from the 4-pK model. The calculated quantities of each functional group were $0.71 \pm 0.04,0.63 \pm 0.04$, and $1.33 \pm 0.07 \mathrm{mmol} / \mathrm{g}$ for PEIB and $1.17 \pm 0.03,0.58 \pm 0.03$, and $0.46 \pm 0.05 \mathrm{mmol} / \mathrm{g}$ for PAAB. The carboxyl groups of biomaterials showed the $\mathrm{pK}_{\mathrm{a}}$ values in the range of 3.5-5.0 (Yun et al. 2001). In addition, the amount of second groups of PAAB $(1.17 \pm 0.03 \mathrm{mmol} / \mathrm{g})$ was higher than that of RB and PEIB, because the carboxyl groups of PAA were introduced by modification on the biomass surface. Thus, the second groups of 4-pK model might indicate carboxyl group of biomasses. These third groups of 4-pK model were recorded at 7.21 $\pm 0.21,7.39 \pm 0.12$, and $6.31 \pm 0.07$ for RB, PEIB, and PAAB, respectively.

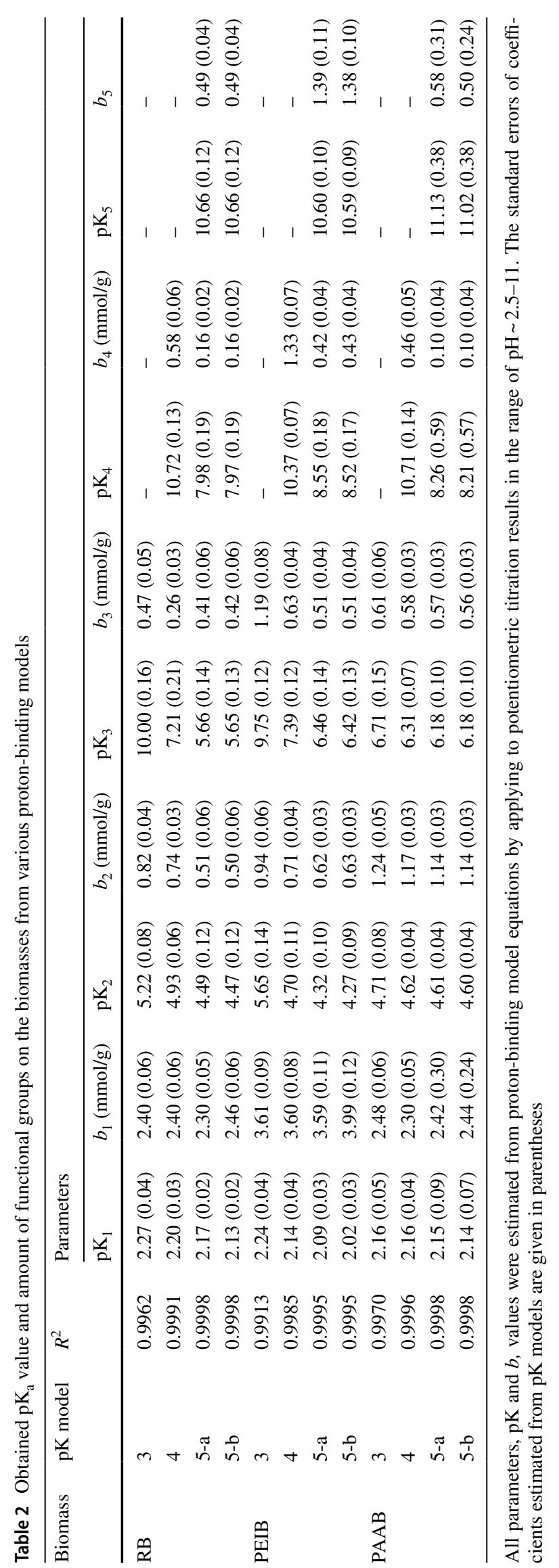


Various functional groups such as phosphoryl, amino, and imidazole groups of biological polymers have $\mathrm{pK}_{\mathrm{a}}$ values around 7 (Yun et al. 2001). However, according to results of FT-IR, the phosphonate groups were located on the biomasses. In addition, the $\mathrm{pK}_{\mathrm{a}}$ value of phosphonate groups showed values similar to the third groups of RB, PEIB, and PAAB (6.1-6.8), possibly indicating the phosphonate group of biomasses. Therefore, the third groups of biomasses can be suggested to be the phosphonate group. The number of third groups of RB, PEIB, and PAAB was calculated as $0.26 \pm 0.03,0.63 \pm 0.04$, and $0.58 \pm 0.03 \mathrm{mmol} / \mathrm{g}$, respectively. The last group of 4-pK model might indicate the amine group, because the amine groups of the biomass were in the range of 8.0-11.0 (Ramrakhiani et al. 2011). The number of last groups of PEIB was 2.29 times higher than that of RB. It might be owing to the enhancement of amine group by PEI modification. In the case of the 5-pK model, two types of 5-pK models were employed to fit the titration results (5-pK-a: 4 anionic and 1 cationic; 5-pK-b: 3 anionic and 2 cationic). According to Table 2, although the different types of functional groups were considered, similar $\mathrm{pK}_{\mathrm{a}}$ values and number of functional groups were obtained from both types of 5-pK models for the same biomass. From the obtained parameters of RB from 5-pK models, the $\mathrm{pK}_{\mathrm{a}}$ values of functional groups were calculated as $4.49 \pm 0.12(4.47 \pm 0.12), 5.66 \pm 0.14(5.65 \pm 0.13)$, $7.98 \pm 0.19(7.97 \pm 0.19)$, and $10.66 \pm 0.12(10.66 \pm 0.12)$ (values in bracket were obtained from 5-pK-b model). Their amounts were calculated to be $0.51 \pm 0.06,0.41 \pm 0.06$, $0.16 \pm 0.02$, and $0.49 \pm 0.04 \mathrm{mmol} / \mathrm{g}$, respectively (in case of 5-pK-b model, $0.50 \pm 0.06,0.42 \pm 0.06,0.16 \pm 0.02$, and $0.49 \pm 0.04 \mathrm{mmol} / \mathrm{g}$, respectively). For PEIB in the case of the 5-pK-a and 5-pK-b models, the $\mathrm{pK}_{\mathrm{a}}$ values were showed at $4.32 \pm 0.10(4.27 \pm 0.09), 6.46 \pm 0.14(6.42 \pm 0.13)$, $8.55 \pm 0.18(8.52 \pm 0.17)$, and $10.60 \pm 0.10(10.59 \pm 0.09)$ (5-pK-b model results are presented in the bracket). Their amounts of functional groups were $0.62 \pm 0.03,0.51 \pm 0.04$, $0.42 \pm 0.04$, and $1.39 \pm 0.11 \mathrm{mmol} / \mathrm{g}$ from the 5 -pK-a model, respectively. The amounts of each functional groups of PEIB were estimated to be $0.63 \pm 0.03,0.51 \pm 0.04,0.43 \pm 0.04$, and $1.38 \pm 0.10 \mathrm{mmol} / \mathrm{g}$ from the 5 -pK-b model, respectively. In $\mathrm{pK}_{\mathrm{a}}$ range of amine groups, the calculated amounts of amine groups of PEIB by both 5-pK models were about 2.8 times higher than those of $\mathrm{RB}$. The $\mathrm{pK}_{\mathrm{a}}$ values of PAAB were evaluated as $4.61 \pm 0.04,6.18 \pm 0.10,8.26 \pm 0.59$, and $11.13 \pm 0.38$ from 5 -pK-a model and $4.60 \pm 0.04,6.18 \pm 0.10$, $8.21 \pm 0.57$, and $11.02 \pm 0.38$ from 5 -pK-b model. The calculated amounts of these functional groups from 5-pK-a and 5-pK-b models were equal to $1.14 \pm 0.03,0.57 \pm 0.03$, $0.10 \pm 0.04$, and $0.58 \pm 0.31 \mathrm{mmol} / \mathrm{g}$ for 5 -pK-a model and $1.14 \pm 0.03,0.56 \pm 0.03,0.10 \pm 0.04$, and $0.50 \pm 0.24 \mathrm{mmol} / \mathrm{g}$ for 5-pK-b model, respectively. In $\mathrm{pK}_{\mathrm{a}}$ range of carboxyl groups, the calculated amounts of carboxyl groups of PAAB by 5-pK models were about 2.3 times higher than those of RB.

From the above results, the quantitative information of functional groups could be calculated by proton-binding model equations. However, the estimation of functional groups using $\mathrm{pK}$ model equations has some limitations: chaotic results of parameters dependent on conditions. In addition, the enhancement of the amounts of functional groups for PEIB and PAAB was not matched to enhance the sorption capacities. The major reason for the previous results might be owing to the very simplified surface nature. Because the biosorbents (biomasses) are natural product complexes, different $\mathrm{pK}_{\mathrm{a}}$ values could be shown in spite of the same functional groups by the influence of located backbones and adjacent other functional groups. Hence, a new approach that can consider different types of functional groups on the biomass surface is proposed to predict the enhancement of sorption capacities by using buffering capacities of functional groups, which are determined from information of potentiometric titration.

\section{Application of buffering capacity for comparison of enhanced sorption capacities}

For determining buffering capacities of main binding sites (i.e., carboxyl and amine groups) from potentiometric titration data, ranges of $\mathrm{pK}_{\mathrm{a}}$ were selected to be $2-5$ and 3-5 for carboxyl groups and 8-11 and 8-10 for amine groups regarding to $\mathrm{pK}_{\mathrm{a}}$ ranges of each binding sites. The buffering capacities of functional groups were calculated as follows:

Buffering Capacity $=\frac{C_{[\mathrm{OH} 2]}-C_{[\mathrm{OH} 1]}}{X}$,

where $X$ is the biomass concentration. $C_{[\mathrm{OH} 1]}$ and $C_{[\mathrm{OH} 2]}$ are the concentrations of $\left[\mathrm{OH}^{-}\right]$ions at specific $\mathrm{pH}$. The concentration of $C_{[\mathrm{OH} 1]}$ and $C_{[\mathrm{OH} 2]}$ was obtained from protonbinding model equation.

The obtained buffering capacities of carboxyl and amine groups in the biomasses from Eq. (4) are summarized in Table 3 . According to Table 3 , the obtained buffering capacities of PAAB from all $\mathrm{pK}$ models in the ranges of carboxyl groups ( $\mathrm{pH} 3-5$ and $\mathrm{pH} 2-5$ ) were about 1.5 and 1.2 times higher than those of RB, respectively, while in case of PEIB, the enhancements of buffering capacities were about 3.6 and 3.1 times higher than RB in the ranges of amine groups, $\mathrm{pH} 8-10$ and $\mathrm{pH} 8-11$, respectively. These enhancements of buffering capacities for binding sites, carboxyl and amine groups, were represented as a function of enhancement of sorption capacities in Fig. 5. As shown in Fig. 5, the enhanced ratio of buffering capacities for carboxyl and amine groups of modified biomasses was similar to the enhanced sorption capacity ratios of modified sorbents. In addition, the buffering capacities obtained by using 5-pK 
Table 3 Calculated buffering capacities of functional groups from parameters of proton-binding models

\begin{tabular}{llllll}
\hline Biomasses & pK model & \multicolumn{4}{l}{ pH range (mmol/g) } \\
\cline { 3 - 6 } & & pH 3-5 & pH 2-5 & pH 8-10 & pH 8-11 \\
\hline RB & 4 & 0.725 & 1.901 & 0.128 & 0.415 \\
& $5-\mathrm{a}$ & 0.739 & 1.836 & 0.167 & 0.419 \\
& $5-\mathrm{b}$ & 0.738 & 1.875 & 0.167 & 0.419 \\
PEIB & 4 & 0.894 & 2.561 & 0.516 & 1.196 \\
& $5-\mathrm{a}$ & 0.895 & 2.512 & 0.603 & 1.330 \\
& $5-\mathrm{b}$ & 0.892 & 2.581 & 0.603 & 1.328 \\
PAAB & 4 & 1.110 & 2.209 & 0.086 & 0.314 \\
& $5-\mathrm{a}$ & 1.112 & 2.256 & 0.112 & 0.320 \\
& $5-\mathrm{b}$ & 1.111 & 2.260 & 0.111 & 0.314 \\
\hline
\end{tabular}

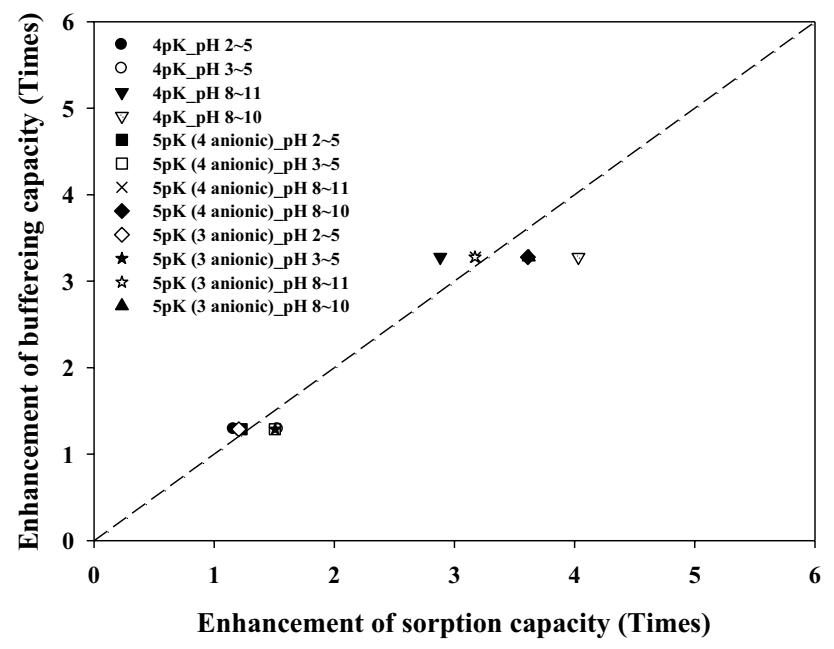

Fig. 5 Comparison of enhancement sorption capacities and buffering capacities for carboxyl group ( $\mathrm{pH} \sim 3-5$ and $\mathrm{pH} \sim 2-5$ ) and amine group ( $\mathrm{pH} \sim 8-10$ and $\mathrm{pH} \sim 8-11)$

models could more exactly represent the enhancement of sorption capacities. At the same time, the enhancements of buffering capacities that are estimated in the $\mathrm{pH}$ range of $2-5$ and $8-11$ were almost similar with enhancements of sorption capacities for pollutants.

Reproducibility of the BCs calculated from potentiometric titration data was validated by comparison of the BCs of RB obtained from potentiometric titration carried out at different initial $\mathrm{pH}(\mathrm{pH} 2$ and $\mathrm{pH} 11)$. The obtained potentiometric titration data of $\mathrm{RB}$ at different initial $\mathrm{pH}$ are presented in the supplementary information as Fig. S1. According to Fig. $\mathrm{S} 1$, the almost similar potentiometric titration curves of RB were showed in both initial $\mathrm{pH}$. In addition, almost similar parameters and fitting lines were obtained from proton-binding model (4-pK model) applied to their titration data. The calculated parameters are summarized in Table S1. According to Table S1, BCs calculated from each $\mathrm{pH}$ range of carboxyl $(\mathrm{pH}$
2-5 and $\mathrm{pH} 3-5)$ and amine ( $\mathrm{pH} 8-10$ and $\mathrm{pH} 8-11)$ groups showed similar values, regardless of initial $\mathrm{pH}$ condition. In the case of initial $\mathrm{pH} 11$, the BCs of carboxyl and amine groups were calculated as $1.955 \mathrm{mmol} / \mathrm{g}(\mathrm{pH} 2-5), 0.786 \mathrm{mmol} / \mathrm{g}(\mathrm{pH}$ $3-5), 0.140 \mathrm{mmol} / \mathrm{g}(\mathrm{pH} 8-10)$, and $0.50 \mathrm{mmol} / \mathrm{g}(\mathrm{pH} 8-11)$, respectively. These acquired results suggest to validate the reproducibility of functional groups comparing method.

\section{Conclusions}

In the present study, quantitative and qualitative information of functional groups in the RB, PAAB, and PEIB was investigated through the potentiometric titration and application of proton-binding models. In addition, from the quantitative parameters obtained from mathematical models, the $\mathrm{BC}$ values for carboxyl and amine groups of biosorbents were estimated in the $\mathrm{pH}$ range of $\mathrm{pH} 2-5$ and $\mathrm{pH} 3-5$, and $\mathrm{pH} 8-10$ and $\mathrm{pH}$ $8-11$, respectively. In the case of carboxyl groups-enhanced $\mathrm{PAAB}$, the BCs of carboxyl groups were $1.5(\mathrm{pH} 3-5)$ and 1.2 ( $\mathrm{pH} 2-5$ ) times higher than those of RB. Meanwhile, the BCs of amine groups on the PEIB were $3.6(\mathrm{pH} \mathrm{8-10)}$ and 3.1 ( $\mathrm{pH} 8-11$ ) times higher than those of RB. These enhancements of buffering capacities of functional groups (carboxyl and amine groups) were similar to those of sorption capacities. The sorption capacity of PAAB $(148.04 \pm 8.06 \mathrm{mg} / \mathrm{g})$ was enhanced to 1.28 times for $\mathrm{BB} 3$ at $\mathrm{pH} 9$ compared with that of RB $(115.21 \pm 2.55 \mathrm{mg} / \mathrm{g})$. In addition, RR4 sorption capacity of PEIB $(403.72 \pm 31.81 \mathrm{mg} / \mathrm{g})$ was 3.27 times higher than that of RB $(123.57 \pm 3.56 \mathrm{mg} / \mathrm{g})$ at $\mathrm{pH} 2$. From these results, positive proportional relationship between sorption capacity and $\mathrm{BC}$ of binding sites was found. Based on this proportionality between sorption capacity and $\mathrm{BC}$ value, a theoretical framework can be inferred that an enhanced sorption capacity for target pollutants can be predicted by comparing BC values of binding site for target pollutants.

Acknowledgements This work was supported by the Korea University and Government of South Korea through the National Research Foundation of Korea (NRF-2017R1A2A1A05001207 and NRF2016R1D1A1B03932773), and Korea Basic Science Institute under the R\&D program (Project No. C38703), supervised by the Ministry of Science, ICT and Future Planning. This research was also supported by a grant from the Marine Biotechnology Program (20170488) funded by the Ministry of Oceans and Fisheries, Korea. Funding was provided by Korea CCS R\&D Center (Grant No. KCRC-2014M1A8A1049278).

Open Access This article is distributed under the terms of the Creative Commons Attribution 4.0 International License (http://creativeco mmons.org/licenses/by/4.0/), which permits unrestricted use, distribution, and reproduction in any medium, provided you give appropriate credit to the original author(s) and the source, provide a link to the Creative Commons license, and indicate if changes were made. 


\section{References}

Bhatnagar A, Vilar VJ, Ferreira C, Botelho C, Boaventura RA (2012) Optimization of nickel biosorption by chemically modified brown macroalgae (Pelvetia canaliculata). Chem Eng J 193:256-266. https://doi.org/10.1016/j.cej.2012.04.037

Cho C-W, Kang SB, Kim S, Yun Y-S, Won SW (2016) Reusable polyethylenimine-coated polysulfone/bacterial biomass composite fiber biosorbent for recovery of $\mathrm{Pd}(\mathrm{II})$ from acidic solutions. Chem Eng J 302:545-551. https://doi.org/10.1016/j.cej.2016.05.091

Choi SB, Yun Y-S (2006) Biosorption of cadmium by various types of dried sludge: an equilibrium study and investigation of mechanisms. J Hazard Mater 138:378-383. https://doi.org/10.1016/j. cej.2016.05.091

Fang L, Cai P, Chen W, Liang W, Hong Z, Huang Q (2009) Impact of cell wall structure on the behavior of bacterial cells in the binding of copper and cadmium. Coll Surf A Physicochem Eng Asp 347:50-55. https://doi.org/10.1016/j.colsurfa.2008.11.04

Hadjoudja S, Deluchat V, Baudu M (2010) Cell surface characterisation of Microcystis aeruginosa and Chlorella vulgaris J Coll. Interface Sci 342:293-299. https://doi.org/10.1016/j.jcis.2009

Kim S, Song M-H, Wei W, Yun Y-S (2015) Selective biosorption behavior of Escherichia coli biomass toward Pd(II) in Pt(IV)Pd(II) binary solution. J Hazard Mater 283:657-662. https://doi. org/10.1016/j.jhazmat.2014

Kim S, Kumar Reddy DH, Choi Y-E, Yun Y-S (2016a) Importance of the coating $\mathrm{pH}$ in fabrication of polyethylenimine-coated polysulfone-Escherichia coli composite fiber sorbent. J Taiwan Inst Chem Eng 66:379-385. https://doi.org/10.1016/j.jtice.2016.06.020

Kim S, Won SW, Cho C-W, Yun Y-S (2016b) Valorization of Escherichia coli waste biomass as a biosorbent for removing reactive dyes from aqueous solutions. Desalin Water Treat 57:20084-20090. https://doi.org/10.1080/19443994.2015.1108235

Kim S, Yun Y-S, Choi Y-E (2018) Development of waste biomass based sorbent for removal of cyanotoxin microcystin-LR from aqueous phases. Bioresour Technol 247:690-696. https://doi. org/10.1016/j.biortech.2017.09.164

Korkmaz F, Ressl S, Ziegler C, Mäntele W (2013) K+-induced conformational changes in the trimeric betaine transporter BetP monitored by ATR-FTIR spectroscopy. Biochim Biophys Acta 1828:1181-1191. https://doi.org/10.1016/j.bbamem.2013.01.004
Mao J, Lee SY, Won SW, Yun Y-S (2010) Surface modified bacterial biosorbent with poly(allylamine hydrochloride): Development using response surface methodology and use for recovery of hexachloroplatinate(IV) from aqueous solution. Water Res 44:5919-5928. https://doi.org/10.1016/j.watres.2010.07.034

Naja G, Mustin C, Berthelin J, Volesky B (2005) Lead biosorption study with Rhizopus arrhizus using a metal-based titration technique. J Coll Interface Sci 292:537-543. https://doi.org/10.1016/j. jcis. 2005.05 .098

Ramrakhiani L, Majumder R, Khowala S (2011) Removal of hexavalent chromium by heat inactivated fungal biomass of Termitomyces clypeatus: surface characterization and mechanism of biosorption. Chem Eng J 171:1060-1068. https://doi.org/10.1016/j. cej.2011.05.002

Singh A, Bajpai J, Bajpai AK (2014) Investigation of magnetically controlled water intake behavior of iron oxide impregnated superparamagnetic casein nanoparticles (IOICNPs). J Nanobiotechnol 12:38. https://doi.org/10.1186/s12951-014-0038-4

Vijayaraghavan K, Yun Y-S (2008) Bacterial biosorbents and biosorption. Biotechnol Adv 26:266-291. https://doi.org/10.1016/j.biote chadv.2008.02.002

Volesky B (2007) Biosorption and me. Water Res 41:4017-4029. https ://doi.org/10.1016/j.watres.2007.05.062

Wei D, Wang B, Ngo HH, Guo W, Han F, Wang X, Du B, Wei Q (2015) Role of extracellular polymeric substances in biosorption of dye wastewater using aerobic granular sludge. Bioresour Technol 185:14-20. https://doi.org/10.1016/j.biortech.2015.02.084

Won SW, Choi SB, Yun YS (2013) Binding sites and mechanisms of cadmium to the dried sewage sludge biomass. Chemosphere 93:146-151. https://doi.org/10.1016/j.chemosphere.2013.05.011

Won SW, Kotte P, Wei W, Lim A, Yun Y-S (2014) Biosorbents for recovery of precious metals. Bioresour Technol 160:203-212. https://doi.org/10.1016/j.biortech.2014.01.121

Yu JX, Li BH, Sun XM, Yuan J, Chi RA (2009) Polymer modified biomass of baker's yeast for enhancement adsorption of methylene blue, rhodamine B and basic magenta. J Hazard Mater 168:11471154. https://doi.org/10.1016/j.jhazmat.2009.02.144

Yun Y-S, Park D, Park JM, Volesky B (2001) Biosorption of trivalent chromium on the brown seaweed biomass. Environ Sci Technol 35:4353-4358. https://doi.org/10.1021/es010866k 